$12-2004$

\title{
Pre-Impact Lower Extremity Posture and Brake Pedal Force Predict Foot and Ankle Forces During an Automobile Collision
}

\author{
Elizabeth C. Hardin \\ Cleveland Clinic Foundation
}

Anne Su

Cleveland Clinic Foundation

Antonie J. van den Bogert

Cleveland State University, a.vandenbogert@csuohio.edu

Follow this and additional works at: https://engagedscholarship.csuohio.edu/enme_facpub

Part of the Biomechanical Engineering Commons

How does access to this work benefit you? Let us know!

\section{Original Citation}

Hardin, E. C., Su, A., and van den Bogert, A. J., 2005, "Pre-Impact Lower Extremity Posture and Brake Pedal Force Predict Foot and Ankle Forces during an Automobile Collision," Journal of Biomechanical Engineering, 126(6) pp. 770-778.

This Article is brought to you for free and open access by the Mechanical Engineering Department at EngagedScholarship@CSU. It has been accepted for inclusion in Mechanical Engineering Faculty Publications by an authorized administrator of EngagedScholarship@CSU. For more information, please contact library.es@csuohio.edu. 


\section{Pre-Impact Lower Extremity Posture and Brake Pedal Force Predict Foot and Ankle Forces During an Automobile Collision}

\section{E. C. Hardin}

\section{A. Su}

\section{A. J. van den Bogert ${ }^{1}$}

Department of Biomedical Engineering, The Cleveland Clinic Foundation, Cleveland, $\mathrm{OH} 44195$
Background: The purpose of this study was to determine how a driver's foot and ankle forces during a frontal vehicle collision depend on initial lower extremity posture and brake pedal force. Method of Approach: A 2D musculoskeletal model with seven segments and six right-side muscle groups was used. A simulation of a three-second braking task found 3647 sets of muscle activation levels that resulted in stable braking postures with realistic pedal force. These activation patterns were then used in impact simulations where vehicle deceleration was applied and driver movements and foot and ankle forces were simulated. Peak rearfoot ground reaction force $\left(F_{R F}\right)$, peak Achilles tendon force $\left(F_{A T}\right)$, peak calcaneal force $\left(F_{C F}\right)$ and peak ankle joint force $\left(F_{A J}\right)$ were calculated. Results: Peak forces during the impact simulation were $476 \pm 687 N\left(F_{R F}\right), 2934 \pm 944 \mathrm{~N}$ $\left(F_{C F}\right)$ and $2449 \pm 918 \mathrm{~N}\left(F_{A J}\right)$. Many simulations resulted in force levels that could cause fractures. Multivariate quadratic regression determined that the pre-impact brake pedal force $(P F)$, knee angle $(K A)$ and heel distance $(H D)$ explained $72 \%$ of the variance in peak $F_{R F}, 62 \%$ in peak $F_{C F}$ and $73 \%$ in peak $F_{A J}$. Conclusions: Foot and ankle forces during a collision depend on initial posture and pedal force. Braking postures with increased knee flexion, while keeping the seat position fixed, are associated with higher foot and ankle forces during a collision.

Keywords: Musculoskeletal Model, Simulation, Vehicle Safety, Injury, Lower Extremity

\section{Introduction}

Lower limb injuries from an automobile collision can cause permanent impairment and disability $[1-4]$ and rank second in vehicle injury cost $[5,6]$. Although seatbelts and airbags ease injuries to life-threatening organs, they do little to avert lower extremity injuries [7-9]. Not surprisingly, injuries to the extremities are rising while head and chest injuries are decreasing [5,8]. Thus, it is essential to diminish the risk of these injuries in the future.

Lower extremity posture during braking modifies the injury risk to the lower extremities [10-12]. Although various foot postures can be used to brake a car in a collision $[11,12]$, experiments with cadaver surrogates have shown that a plantarflexed foot can increase the vehicle injury risk compared to a dorsiflexed foot [10]. As well, the in vivo initial knee angle can significantly influence the ankle moment after a pendulum impact [13]. Numerical simulations of impact during human running have demonstrated that peak impact forces can be influenced by ankle and knee angles at footstrike [14], and similar mechanisms may play a role during vehicle collisions.

The brake pedal force applied by the driver also influences joint loading. The muscle activation necessary to produce force on the brake pedal can intensify lower extremity forces during a collision [15]. Joint loading during braking might therefore be reduced with a specific muscle activation pattern in the lower extremities, as has been demonstrated computationally for other movement tasks $[16,17]$. Tasks such as braking, indeed most movements, can be accomplished with numerous combinations of muscle activity be-

${ }^{1}$ A. J. van den Bogert, Ph.D., Department of Biomedical Engineering (ND-2), Cleveland Clinic Foundation, 9500 Euclid Avenue, Cleveland, OH 44195. E-mail bogert@bme.ri.ccf.org; phone: (216) 444-5566; fax: (216) 444-9198.

Contributed by the Bioengineering Division for publication in the JOURNAL OF BIOMECHANICAL ENGINEERING. Manuscript received by the Bioengineering Division September 26, 2003; revision received June, 11, 2004. Associate Editor: Philip V. Bayly. cause of the redundancy of muscle function in the human body [18]. Accordingly, there are many different limb positions and pedal forces that could be used while braking, some of which may be safer than others. Specifically, it is not known how foot and ankle forces during a collision depend on the lower extremity posture and pedal force adopted by the driver while braking. In vivo experiments are not feasible, and experiments with cadavers or crash dummies have the limitation that mechanical properties of active muscles are not simulated. These muscle properties can cause substantially increased skeletal tension both from increased activation and from rapid stretching during impact due to the force-velocity and force-length relationships inherent in active muscle tissue [19]. Experiments with crash dummies and cadavers are also disadvantageous due to time and monetary cost. This makes it difficult to use these paradigms to explore the large space of possible braking postures and brake pedal forces. Finite element-based computational models have similar limitations. Useful insight into questions such as these can be obtained with forward dynamic multibody models that include realistic muscle properties $[14,16,17]$.

The aim of this study was to determine how foot and ankle forces during a frontal collision depend on lower extremity posture and pedal force, by using a computational forward dynamics musculoskeletal model with realistic muscle properties.

\section{Methods}

A 2-D forward dynamics musculoskeletal model was used to simulate active braking with the right foot (Fig. 1). The model had right and left legs, each consisting of three rigid bodies: (a) thigh, (b) lower leg, and (c) foot. The pelvis, trunk, arms and head were represented by one segment [20]. The 50th percentile male was modeled which stipulated a body mass of $76.6 \mathrm{~kg}$, a height of 1.75 $\mathrm{m}$, and appropriate segment lengths [21]. Segment masses and inertial properties were calculated with a method based on Demp- 


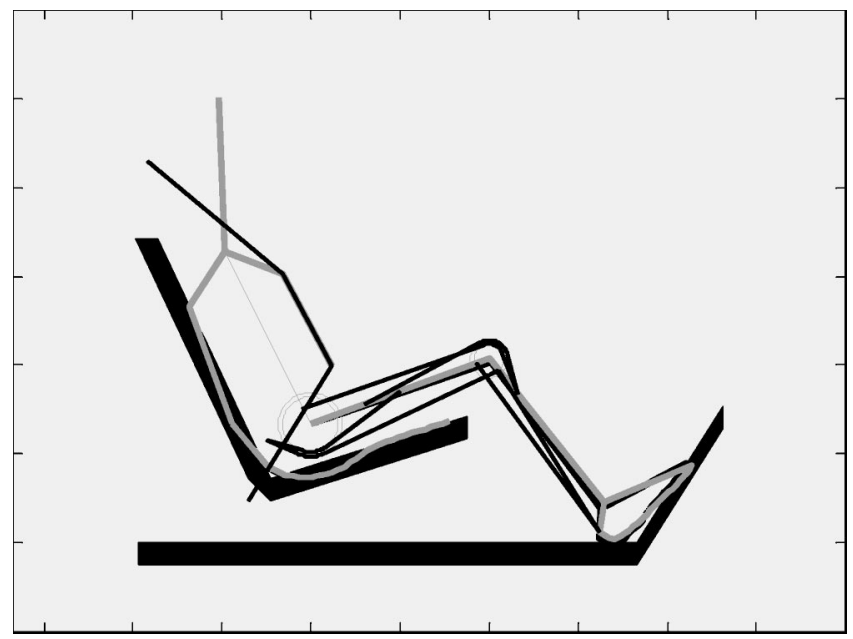

Fig. 1 The seven body segments represented in the model (gray), the six muscles (black), the contact surfaces and the seat restraints. The passive left leg is resting on the toepan and the active right leg is braking. The model is shown while braking prior to the crash with muscles at minimal activation and with a brake pedal force of $400 \mathrm{~N}$.

ster's work [20,22]. All segments were connected by frictionless hinge joints. The model had nine kinematic degrees of freedom and equations of motion were generated using SD/FAST (PTC, Needham MA, USA). The model was implemented with forward dynamics to simulate motion under the influence of vehicle deceleration and muscle activation.

Six muscle groups were included in the right lower extremity: (a) the glutei, (b) hamstrings, (c) rectus femoris, (d) vasti, (e) gastrocnemius, and (e) soleus. Each muscle group was represented by a Hill-based model with two components: a contractile element (CE) and series elastic element (See, Fig. 2). Muscles were given constant moment arms and properties (Table 1) that have been used previously [23]. The CE and SEE were described by the equations of McLean et al. [24]. Passive elastic properties were modeled as torques in the hip, knee and ankle joints. These torques were functions of two joint angles [25] because several muscles incorporated were two joint muscles. This feature of the model incorporated passive coupling between joints, which is characteristic of biarticular muscles.

Contact surfaces in the vehicle were modeled as line segments according to dimensions for a 1992 Ford Taurus from the Ford Motor Company (Detroit, MI, USA; Fig. 1). Contact elements were placed between each foot and toepan and floorpan, between each thigh and seat pan, and between the torso and seat back. Each contact element permitted deformation perpendicular to the contact surface producing a force perpendicular to the surface depending on penetration $p$ and its velocity $\dot{p}$.

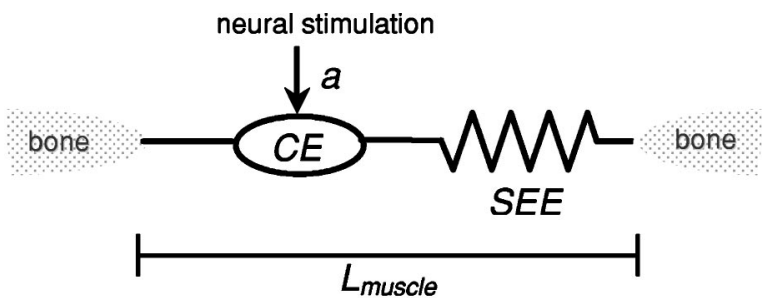

Mechanical properties:

$F_{C E}=f_{1}\left(L_{C E}, d L_{C E} / d t, a\right)$

$$
F_{\text {SEE }}=f_{2}\left(L_{S E E}\right)
$$

State equation:

Fig. 2 A two-element Hill-based model was used to represent active muscles

$$
F_{\text {normal }}=a \cdot p^{b}+c \cdot p^{d} \cdot \dot{p}^{e}
$$

Contact between the feet, and toepan and floorpan was modeled by 22 discrete contact elements [26] divided into three regions (rearfoot, midfoot and forefoot). Parameters for the contact points were chosen to fit experimental force-deformation data from an in vivo dynamic impact test on the heel and soft shoe [27]: $a$ $=8839, b=1.066, c=376.8, d=0.4456, e=0.3896$, with $F, p$ and $\dot{p}$ expressed in $\mathrm{N}, \mathrm{m}$, and $\mathrm{m} \cdot \mathrm{s}^{-1}$, respectively. Contact between the thigh segments and seat pan was modeled by 30 discrete contact elements per thigh. The contact model between the torso and the seat back was composed of 2 discrete contact elements, at the fourth thoracic and at the fifth lumbar vertebrae [21]. These seat pan and seat back contact elements were linear viscoelastic elements with elastic properties determined by assuming a total seat deformation of $2 \mathrm{~cm}$ under full body weight $\left(k_{\text {seatpan }}\right.$ $\left.=657.12 \mathrm{~N} \cdot \mathrm{m}^{-1} ; k_{\text {seatback }}=19,715 \mathrm{~N} \cdot \mathrm{m}^{-1}\right)$ and critical damping properties $\left(c_{\text {seatpan }}=57.92 \mathrm{~N} \cdot \mathrm{s} \cdot \mathrm{m}^{-1} ; c_{\text {seatback }}=1737.5 \mathrm{~N} \cdot \mathrm{s} \cdot \mathrm{m}^{-1}\right)$. Forces parallel to the surface of all contact points were generated with a Coulomb friction model approximation [17], using a friction coefficient of 1.0. The lap belt restraint was modeled as a linear spring between the vehicle and torso allowing $15 \%$ deformation at $11,120 \mathrm{~N}$ [28], providing a force to the maximum abdominal protrusion [21]. The shoulder belt restraint was modeled as a spring, which permitted $100 \%$ deformation at $11,120 \mathrm{~N}$ and provided a force to the substernum [21].

Multiple sets of muscle stimulation levels were randomly generated. Each set was used as input for a $3.0 \mathrm{~s}$ long simulation of braking. In these simulations, the model sat in the seat without muscle stimulation for $2.0 \mathrm{~s}$ and then had muscle stimulation values ramped up to the specified level in $0.5 \mathrm{~s}$ and then held constant for $0.5 \mathrm{~s}$. A set of muscle stimulation levels was accepted if it produced a final braking force and heel distance (position) values prior to the crash of $0-1200 \mathrm{~N}$ and $0-0.30 \mathrm{~m}$, respectively. It was assumed that the brake pedal was fully depressed to the toepan surface. The heel distance was defined as the horizontal

Table 1 Parameters of the muscle models. $F_{\max }$ is the maximal isometric force of the CE. $L_{\text {muscle }}$ is the length of the muscle when the hip, knee and ankle are positioned at $0 \mathrm{deg} ; L_{\text {slack }}$ is the slack length of the SEE; $L_{C E o p t}$ is the optimal length of the CE; width is the maximal relative length change of the CE; $M A_{\text {hip, knee, ankle }}$ are the moment arms of the muscles at the hip, knee or ankle; $N A$

\begin{tabular}{|c|c|c|c|c|c|c|c|c|}
\hline Muscle & $\begin{array}{c}F_{\max } \\
(\mathrm{N})\end{array}$ & $\begin{array}{l}L_{\text {muscle }} \\
\quad(\mathrm{m})\end{array}$ & $\begin{array}{l}L_{\text {slack }} \\
(\mathrm{m})\end{array}$ & $\begin{array}{l}L_{\text {CEopt }} \\
(\mathrm{m})\end{array}$ & $\begin{array}{c}\text { width } \\
\text { (proportion } \\
\text { of } L_{\text {CEopt }} \text { ) }\end{array}$ & $\begin{array}{l}M A_{h i p} \\
\quad(\mathrm{~m})\end{array}$ & $\begin{array}{l}M A_{\text {knee }} \\
(\mathrm{m})\end{array}$ & $\begin{array}{c}M A_{\text {ankle }} \\
\quad(\mathrm{m})\end{array}$ \\
\hline glutei & 1705 & 0.271 & 0.157 & 0.200 & 0.625 & -0.062 & NA & NA \\
\hline hamstrings & 1770 & 0.383 & 0.334 & 0.104 & 1.197 & -0.072 & -0.034 & NA \\
\hline rectus femoris & 663 & 0.474 & 0.398 & 0.081 & 1.443 & 0.034 & 0.050 & NA \\
\hline Vasti & 7403 & 0.271 & 0.223 & 0.093 & 0.627 & NA & 0.042 & NA \\
\hline Gastrocnemius & 1639 & 0.404 & 0.420 & 0.055 & 0.888 & NA & -0.02 & -0.053 \\
\hline Soleus & 3883 & 0.201 & 0.245 & 0.055 & 1.039 & NA & NA & -0.053 \\
\hline
\end{tabular}
denotes that the property is not applicable. 


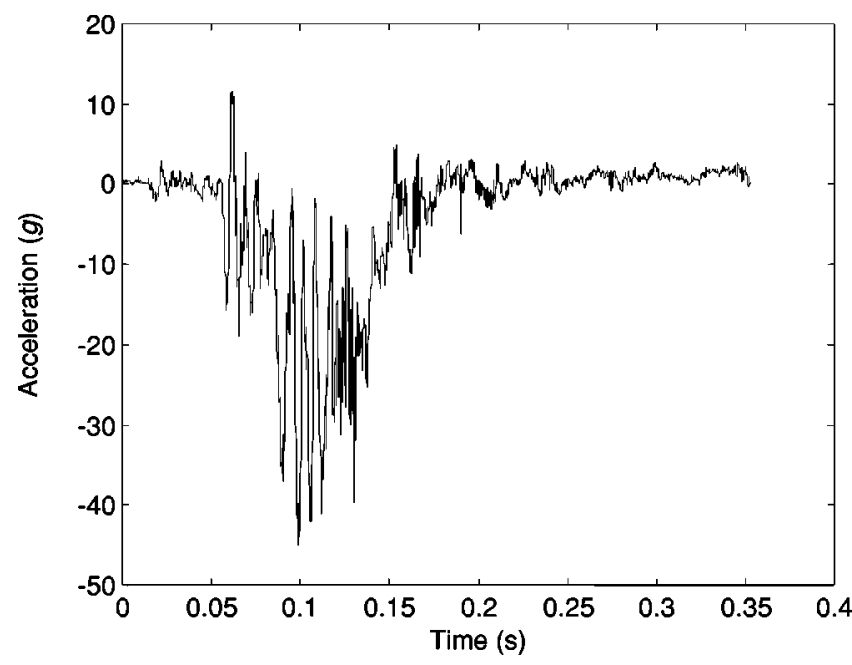

Fig. 3 The deceleration pulse applied to the contact surfaces of the model obtained from the National Highway Transportation and Safety Administration (NHTSA, crash \#2075)

distance from the posterior calcaneus to the toepan surface. These criteria resulted in 4209 valid stimulation patterns out of 10,000 patterns tested. A further criterion was applied to eliminate those simulations where the model pushed itself out of the seat. Specifically, the center of mass of the segment representing the pelvis, trunk, arms and head was required to be less than $0.60 \mathrm{~m}$ above the intersection between seat and backrest. This resulted in 3647 stimulation patterns, which were accepted for use in the subsequent impact simulations.

To simulate a frontal impact, vehicle deceleration data were obtained from the National Highway Transportation and Safety Administration (NHTSA, http://www-nrd.nhtsa.dot.gov/database/ nrd-11/veh_db.html, test no. 2075; Fig. 3). This test was a vehicle-to-vehicle frontal impact test of a 1992 Ford Taurus LX with a speed of $61.5 \mathrm{~km} \cdot \mathrm{h}^{-1}$ and was used in a previous computational study on other types of lower extremity injury [29]. The data were twice integrated and used to generate horizontal displacement of the vehicular contact surfaces. Toepan intrusion was not included in the model. Impacts were simulated with the following kinematic and muscle property input obtained from the 3647 models: (a) initial segment positions and velocities, (b) muscle contractile element lengths, and (c) muscle stimulation levels. Each model was placed on the vehicle contact surfaces and crash motion data were applied to the contact surfaces. The following variables were obtained from each impact simulation: (a) peak rearfoot ground reaction force $\left(F_{\mathrm{RF}}\right)$, (b) peak Achilles tendon force $\left(F_{\mathrm{AT}}\right)$, (c) peak calcaneal force $\left(F_{\mathrm{CF}}\right)$, and $(\mathrm{d})$ peak ankle joint force $\left(F_{\mathrm{AJ}}\right)$. The calcaneal force was calculated as the sum of the rearfoot ground reaction force and Achilles tendon force $\left(F_{\mathrm{CF}}=\left|\begin{array}{ll}\vec{F}_{\mathrm{RF}} & \vec{F}_{\mathrm{AT}}\end{array}\right|\right)$.
Table 2 The mean (SD) of pre-impact brake pedal force, lower extremity joint angles, and heel distance generated by the braking simulations. A joint angle of 0 deg refers to neutral posture. A hip in flexion is denoted by a positive hip angle. A knee in flexion is denoted by a negative knee angle. A foot in plantarflexion is a negative ankle angle. The heel distance is defined as the horizontal distance from the posterior calcaneus to the toepan surface and was restricted a range of $0-0.3 \mathrm{~m}$.

\begin{tabular}{ccc}
\hline \hline Pre-impact variables & Mean & $S D$ \\
\hline Pedal force $(\mathrm{N})$ & 597 & 202 \\
Hip angle $(\mathrm{deg})$ & 82 & 11 \\
Knee angle $(\mathrm{deg})$ & -76 & 12 \\
Ankle angle $(\mathrm{deg})$ & -22 & 25 \\
Heel distance $(\mathrm{m})$ & 0.132 & 0.069 \\
\hline \hline
\end{tabular}

Multivariate polynomial regression was used to examine how the pre-impact braking force (BF), knee angle (KA) and heel distance from the toepan (HD) could explain the peak forces during the crash $\left(F_{\mathrm{RF}}, F_{\mathrm{CF}}\right.$, and $\left.F_{\mathrm{AJ}}\right)$. For each dependent variable $y$ $\left(F_{\mathrm{RF}}, F_{\mathrm{CF}}\right.$, or $\left.F_{\mathrm{AJ}}\right)$, the following equation was fit to the data:

$$
y=a \sum_{i=1}^{3} b_{i} x_{i} \sum_{i=1}^{3} \sum_{j=1}^{i} c_{i j} x_{i} x_{j}
$$

where $x_{1}, x_{2}$ and $x_{3}$ are, respectively, the pre-impact variables $\mathrm{BF}, \mathrm{HD}$ and KA. Regression using least squares was performed with the function REGRESS in the Matlab Statistics Toolbox (Mathworks Inc., Natick, MA) with significance set at $p<0.05$.

\section{Results}

The braking simulations generated prior to the crash resulted in a wide range of lower extremity postures that were qualitatively realistic (Table 2). The average brake pedal force was $597 \mathrm{~N}$ (Table 2).

The average peak external rearfoot force $\left(F_{\mathrm{RF}}\right)$ generated during the impact simulations was $476 \mathrm{~N}$ with a large variability (Table 3). There were numerous simulations where the rearfoot did not make contact with the vehicle surface during the collision resulting in no external force on the rearfoot (Fig. 4). The average peak calcaneal force $\left(F_{\mathrm{CF}}\right)$ was $2934 \mathrm{~N}$, six times greater than peak $F_{\mathrm{RF}}$, with a large variability (Table 3$)$. The average peak ankle force $\left(F_{\mathrm{AJ}}\right)$ was $4225 \mathrm{~N}$, nine times greater than peak $F_{\mathrm{RF}}$, also with a large variability (Table 3 ). The collision simulations produced a wide range of possible combinations of the pre-impact variables $(\mathrm{BF}, \mathrm{HD}$ and $\mathrm{KA})$ and peak post-impact forces $\left(F_{\mathrm{RF}}\right.$, $F_{\mathrm{CF}}$ and $F_{\mathrm{AJ}}$; Figs. 4-6). There were no obvious univariate relationships between pre- and post-impact variables, although some clustering was observed.

The multivariate polynomial regression analysis found relationships between pre-impact and post-impact variables and quantified the proportion of explained variance $\left(r^{2}\right.$, Table 3$)$. The postimpact measures with the greatest proportion of explained

Table 3 Statistical information for the three post-impact variables from the simulated collision: mean (SD), root-mean-squared error $(R M S E)$, multiple polynomial regression coefficient $\left(r^{2}\right)$, and statistical significance ( $p$-value) $(n=3647)$. The peak rearfoot force $\left(F_{\mathrm{RF}}\right)$ had the lowest RMSE while the peak calcaneal force had the highest RMSE. The proportion of the explained variability $\left(r^{2}\right)$ by the three pre-impact variables was greatest for $F_{\mathrm{RF}}$ and $F_{\mathrm{AJ}}$. The pre-impact variables were statistically significant predictors of the post-impact forces ( $F$-statistic, $p$-value).

\begin{tabular}{|c|c|c|c|c|c|}
\hline Post-impact variables & Mean $(S D)$ & RMSE & $r^{2}$ & $F$-statistic & $p$-value \\
\hline $\begin{array}{c}\text { Peak rearfoot force } \\
\left(F_{\mathrm{RF}}, N\right)\end{array}$ & $476(687)$ & 362.21 & 0.72 & 1049.56 & $<0.005$ \\
\hline $\begin{array}{l}\text { Peak calcaneal force } \\
\qquad\left(F_{\mathrm{CF}}, N\right)\end{array}$ & 2934 (944) & 581.16 & 0.62 & 662.37 & $<0.005$ \\
\hline $\begin{array}{l}\text { Peak ankle force } \\
\left(F_{\mathrm{AJ}}, N\right)\end{array}$ & 4425 (918) & 478.02 & 0.73 & 1075.20 & $<0.005$ \\
\hline
\end{tabular}



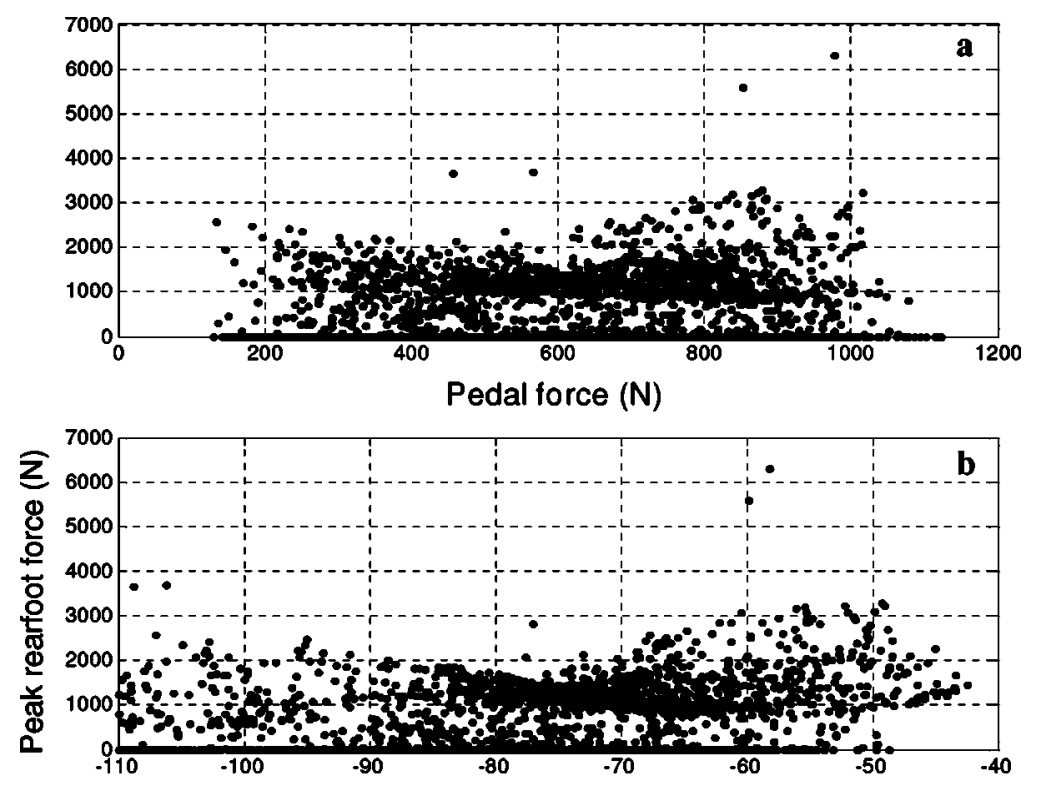

Braking knee angle (degrees)

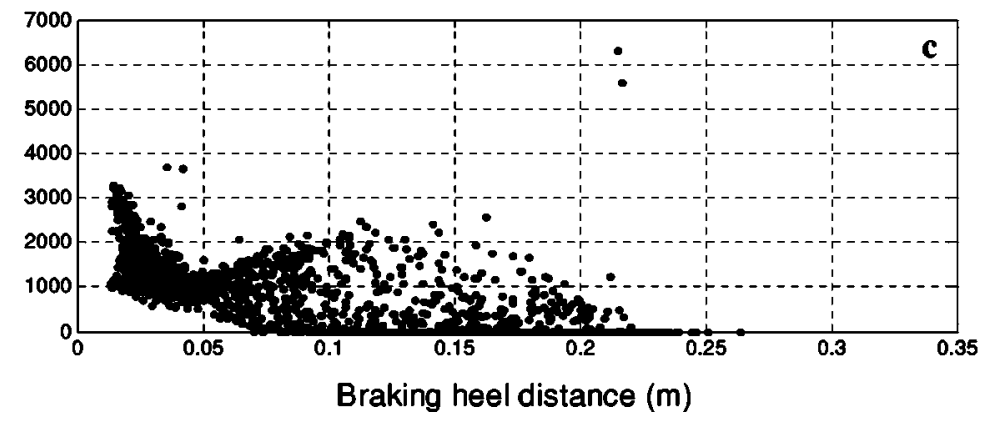

Fig. 4 Peak external force applied to the rearfoot $\left(F_{\mathrm{RF}}\right)$ during the crash for all simulations and its relationship to the pre-impact variables, $B F(a), H D$ (b), and KA (c). HD is the distance of the heel from the toepan origin. KA equal to 0 deg signifies a full knee extension and -90 deg signifies 90 deg of knee flexion. There was a large variability in peak $F_{\mathrm{RF}}$. In many simulations, the rearfoot did not make contact with the vehicle surface during the collision resulting in a lack of external force on the rearfoot.

variance were those for $F_{\mathrm{RF}}$ and $F_{\mathrm{AJ}}\left(r^{2}=0.72\right.$ and 0.73 , respectively) - while greater than half of the variance was explained for $F_{\mathrm{CF}}\left(r^{2}=0.62\right)$. The peak $F_{\mathrm{RF}}$ had the lowest rootmean-square fit error $(R M S E)$ while peak $F_{\mathrm{CF}}$ had the highest RMSE (Table 3). The three pre-impact variables were found to be statistically significant predictors for the three post-impact lower extremity forces $(p<0.005)$.

The relationships of $\mathrm{BF}, \mathrm{HD}$ and $\mathrm{KA}$ to the post-impact forces were highly nonlinear and there were important interactions between pairs of pre-impact variables (Table 4). The regression coefficients for prediction of each of the post-impact lower extremity forces are listed in Table 4 . The regression model was used to identify combinations of input variables that were associated with high forces during the collision (Fig. 7).

\section{Discussion}

The aim of this study was to determine how foot and ankle forces during a frontal collision depend on the lower extremity posture and brake pedal force. Through computational modeling we found that we were able to generate numerous impact simulations, each starting from a different, but realistic, initial brake pedal force and lower extremity posture. The impact simulations showed complex relationships between the pre-impact variables (lower extremity posture and pedal force) and the post-impact variables (peak foot and ankle forces, Figs. 4-6). We quantified these relationships using multiple polynomial regression and found them to be nonlinear with interactions between the independent variables. A large proportion of variability $(0.62-0.73)$ in foot and ankle collision forces could be explained by lower extremity posture and braking force and it was possible to identify the combinations of posture and pedal force that lead to an increased risk of foot and ankle injury.

The method applied to discern the relationships between the pre- and post-impact variables was unique in that the numerical simulations were driven by 3647 random combinations of activation levels for the six muscles. These inputs produced a wide range of realistic lower extremity postures and brake pedal forces, and these pre-impact conditions were then used as initial conditions for the impact simulations. The output of each impact simulation consisted of external force on the rearfoot and internal forces on the calcaneus and in the ankle joint. The advantage of producing a large data set facilitated the examination of complex relationships between several pre- and post-crash variables. The two-dimensional rigid multibody model with muscle properties was simple enough that this data set with 3647 impacts could be generated in a reasonable time (33 seconds per impact simulation on a Linux system with a $900 \mathrm{MHz}$ AMD Athlon processor and GNU C compiler). Generating a similar data set would not be 

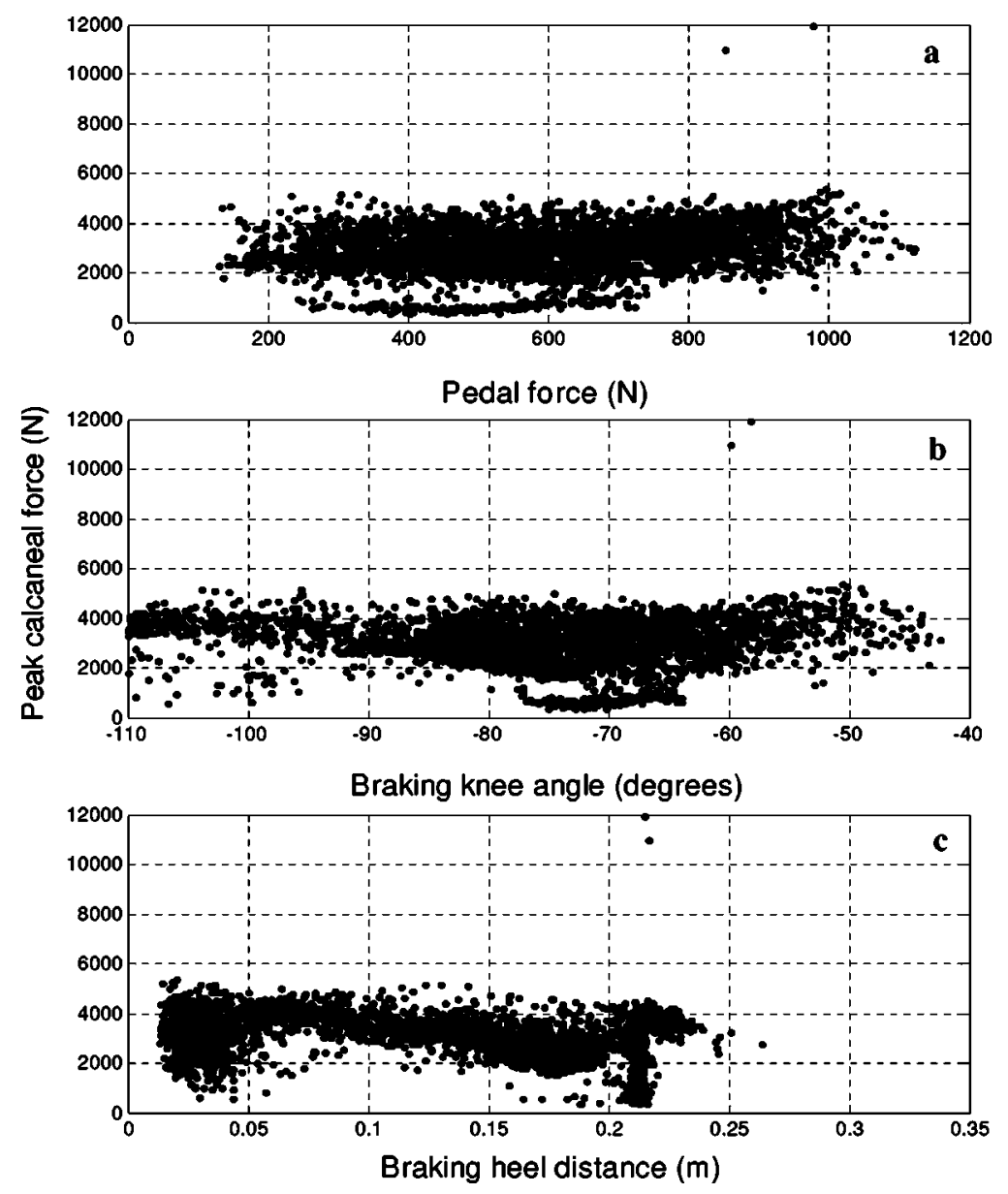

Fig. 5 Peak calcaneal force $\left(F_{\mathrm{CF}}\right)$ during the crash for all simulations and its relationship to BF $(a), H D(b)$, and KA $(c)$. HD is the distance of the heel from the toepan origin. KA equal to 0 deg signifies a full knee extension and -90 deg signifies 90 deg of knee flexion.

computationally feasible with a dynamic finite element model. In vitro studies have the same disadvantage of limited data sets $[10,15,30]$, especially when specimens are tested near failure loads. Furthermore, it is difficult to determine the influence of muscle activation with in vitro studies. In vivo human subject studies can provide insight into the influence of muscle activation, but have the restriction that experiments can only be done under conditions that are well below the injury threshold.

The static braking simulations produced results that were consistent with previous studies. Our simulations produced an average brake pedal force of $597 \mathrm{~N}$ (Table 2), similar to what was found in vivo $(630 \mathrm{~N})$ [11]. In addition, average heel distance during braking was similar to in vivo data [11]. These in vivo measurements, from subjects in a driving simulator, revealed that subjects' heels were initially kept on the floor during braking with just half of the participants using plantarflexion to increase pedal force. Their mean peak plantarflexion was $15 \mathrm{deg}$ ( $\pm 2 \mathrm{deg})$ during braking at a heel distance of $0.12 \mathrm{~m}$. This compares favorably to the 22 deg mean plantarflexion and $0.13 \mathrm{~m}$ mean heel distance generated by our braking simulations, although our standard deviation was greater. The Achilles tendon force $\left(F_{\mathrm{AT}}\right)$ during braking has been estimated in vivo and incorporated into other computational models in the range of $960 \mathrm{~N}-3000 \mathrm{~N}[11,15,31]$. We found similar results for peak $F_{\mathrm{AT}}$ from our braking simulations, $800 \mathrm{~N}-3000 \mathrm{~N}$ (minimal muscle activation-maximal muscle activation).

Post-impact forces generated by our model were generally consistent with other models, though there were some notable differ- ences. Peak ankle joint forces ranged from 2 to $7 \mathrm{kN}$, which is similar to values found in other numerical models [12,15] and cadaver models [32]. Rearfoot forces were $0-3 \mathrm{kN}$, which is considerably lower than the $4 \mathrm{kN}$ predicted by the computational model of Kitagawa and coworkers [15], but their contact force reported was that from the whole foot rather than the rearfoot alone as reported from our results. Differences may also be due to the method used to represent muscles, with Kelvin elements [15] or with joint rotational stiffness [12]. These models may not have had the high short-range stiffness that is characteristic of muscle tissue when stretched at high speed [19], a property that is represented well in a Hill-based muscle model. Hill-based muscle models have been incorporated in one other model of lower-extremity injury in vehicle collision [33], in a single simulation at an activation level of $30 \%$. This model predicted a much higher ankle force than the present study, but this was a simulation of toepan intrusion rather than vehicle deceleration. It should be noted that their muscle model [33] did not appear to include series elasticity, which could have resulted in too much short-range muscle stiffness [19] and thus an overestimation of stretch-induced muscle forces.

Our results are representative for accidents with deceleration from vehicle-to-vehicle frontal impact at $61.5 \mathrm{~km} \cdot \mathrm{h}^{-1}$, but there are limitations in several aspects. First, the model was twodimensional. We accepted this limitation because it is known that mechanisms for calcaneal fractures do not involve out of plane forces or movements [7,34]. Similarly, axial joint loading is the 

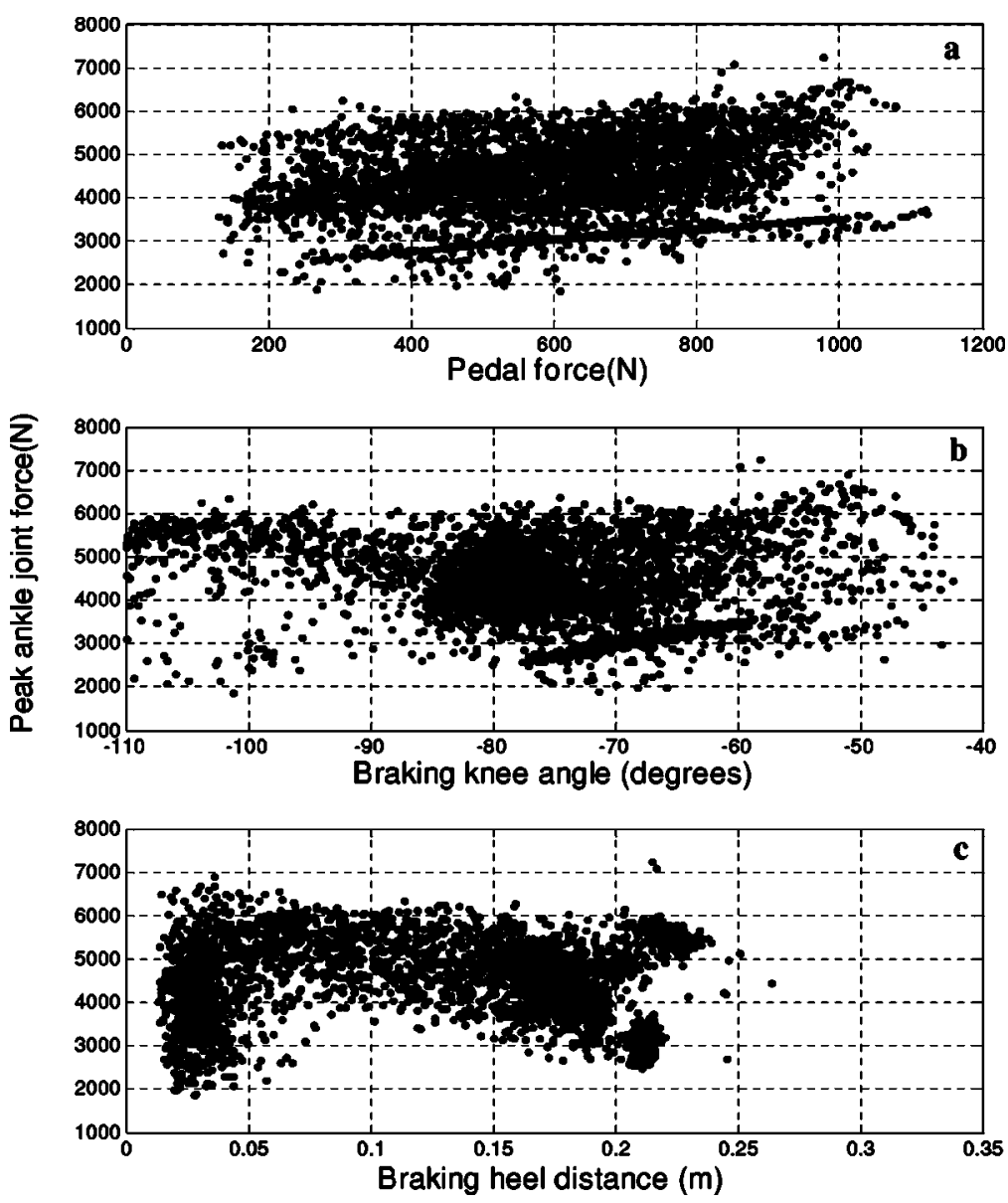

Fig. 6 Peak ankle force $\left(F_{\mathrm{AJ}}\right)$ during the crash for all simulations and its relationship to BF (a), HD (b), and KA (c). HD is the distance of the heel from the toepan origin. KA equal to 0 deg signifies a full knee extension and -90 deg signifies 90 deg of knee flexion.

primary mechanism responsible for pilon fractures [32]. We also found that peak forces occurred within $60 \mathrm{~ms}$ of the vehicle impact, making it likely that out of plane motion would not yet be large enough to have influenced peak forces. A three-dimensional model would be needed for examining other injury mechanisms, such as those due to foot inversion and abduction during braking $[2,12]$. A second limitation was not modeling toepan intrusion. This was done in order to isolate the effect of deceleration alone on foot and ankle injuries $[2,7,10]$ and because most foot and ankle injuries seem to occur prior to intrusion [15]. Intrusion may be included, however, in future applications of this model because the data set used (Test \#2075 in the NHTSA database) is one of the few that includes toepan intrusion measurements. A significant limitation of all biomechanical models for traumatic injury is that they cannot be validated under injury conditions. Useful data for model validation may be obtained eventually from continuous recordings of vehicle and driver dynamics during accidents [35]. An earlier version of the present model was able to predict external forces during running [17], but this validation did not include seated impacts, and impacts at force levels that can produce fractures.

Table 4 The coefficients for the regression equation (1) to predict the peak post-impact forces in the rearfoot, calcaneus and ankle based on the pre-impact braking force (BF), heel distance (HD) and knee angle (KA). Numerical values of the coefficients are based on the following units: forces in $\mathrm{N}$, heel distance in $\mathrm{m}$, knee angle in deg. Error estimates are given in parentheses.

\begin{tabular}{cccc}
\hline \hline Coefficients & Peak rearfoot force $\left(F_{\mathrm{RF}}\right)$ & Peak calcaneal force $\left(F_{\mathrm{CF}}\right)$ & Peak ankle force $\left(F_{\mathrm{AJ}}\right)$ \\
\hline$a_{0}$ & $1.741(0.764) \times 10^{3}$ & $-1.257(0.123) \times 10^{4}$ & $-1.195(0.101) \times 10^{4}$ \\
$b_{1}(\mathrm{BF})$ & $3.184(0.852) \times 10^{0}$ & $1.286(0.137) \times 10^{1}$ & $1.564(0.112) \times 10^{1}$ \\
$b_{2}(\mathrm{HD})$ & $-1.962(0.135) \times 10^{4}$ & $-3.617(0.216) \times 10^{4}$ & $-1.526(1.779) \times 10^{3}$ \\
$b_{3}(\mathrm{KA})$ & $7.539(14.063) \times 10^{0}$ & $-3.120(0.226) \times 10^{2}$ & $-2.421(0.186) \times 10^{2}$ \\
$c_{12}(\mathrm{BF} \cdot \mathrm{HD})$ & $5.903(0.755) \times 10^{0}$ & $1.509(0.121) \times 10^{1}$ & $-8.310(0.997) \times 10^{0}$ \\
$c_{13}(\mathrm{BF} \cdot \mathrm{KA})$ & $4.668(0.752) \times 10^{-2}$ & $1.750(0.121) \times 10^{-1}$ & $1.226(0.099) \times 10^{-1}$ \\
$c_{23}(\mathrm{HD} \cdot \mathrm{KA})$ & $2.327(1.198) \times 10^{1}$ & $-5.547(0.192) \times 10^{2}$ & $-5.119(0.158) \times 10^{2}$ \\
$c_{11}\left(\mathrm{BF}^{2}\right)$ & $-1.022(0.276) \times 10^{-3}$ & $9.970(4.430) \times 10^{-4}$ & $-1.337(0.364) \times 10^{-3}$ \\
$c_{22}\left(\mathrm{HD}^{2}\right)$ & $3.867(0.229) \times 10^{4}$ & $-8.603(0.367) \times 10^{4}$ & $-1.423(0.030) \times 10^{5}$ \\
$c_{33}\left(\mathrm{KA}^{2}\right)$ & $2.328(0.663) \times 10^{-1}$ & $-1.494(0.106) \times 10^{0}$ & $-1.186(0.087) \times 10^{0}$ \\
\hline \hline
\end{tabular}




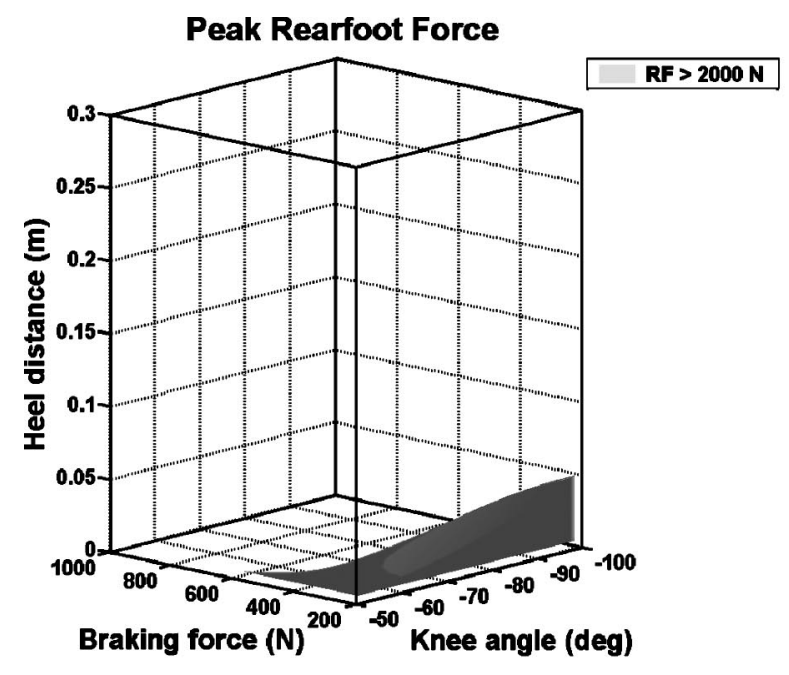

a
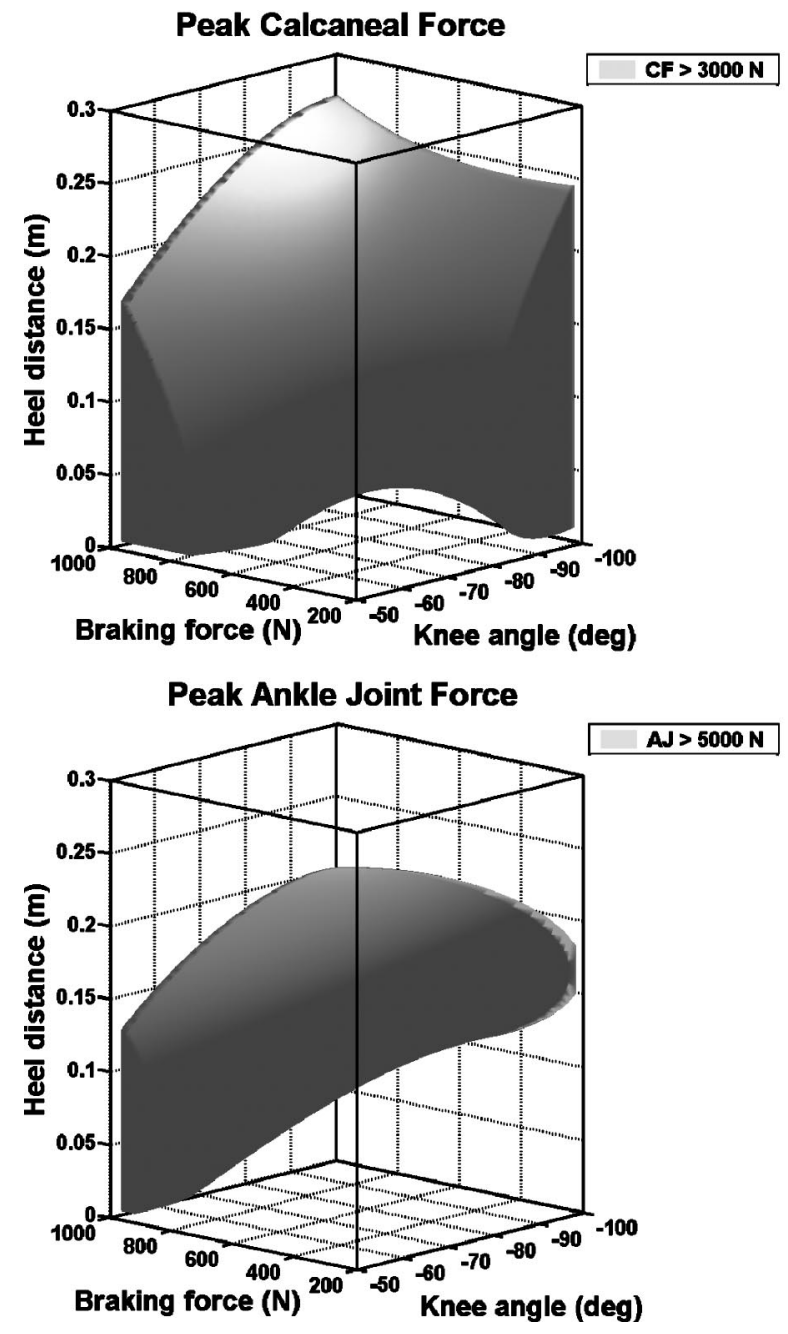

c

Fig. 7 Regions of high injury risk were generated from the regression models for each of the three post-impact variables

If our predictions are valid, toepan intrusion or entrapment of the knee below the instrument panel, which were not included in the simulations, may be required to produce calcaneal fractures during a vehicle collision [34]. The peak external rearfoot force rarely exceeded $3000 \mathrm{~N}$ in the impact simulations (Fig. 4), while at least $4000 \mathrm{~N}$ is required to produce a calcaneal fracture [10]. On the other hand, the sum of the rearfoot contact force and
Achilles tendon force (Fig. 5), which we term "calcaneal force," reached levels of up to $5000 \mathrm{~N}$. This variable is related to bending load in the calcaneus, but its relevance to fracture mechanisms is not well understood. An in vitro study [32] showed that the probability of the calcaneal fracture was very high and independent of tendon force, but the experimental conditions were such that rearfoot force was much higher than the Achilles tendon force during 
impact. Ankle joint force, a variable that is related to pilon (compression) fracture of the distal tibia, reached values of up to 6500 N (Fig. 6), which can cause these fractures [32].

Our model shows that heavy braking may increase the risk of pilon fracture while decreasing the risk of a calcaneal fracture. Sizable pedal forces at an intermediate heel distance were observed to elevate ankle joint force (Fig. $7(c)$ ) while lower pedal forces at a minimal heel distance elevated rearfoot force (Fig. $7(a)$ ). These findings are consistent with those from a cadaver model where Achilles tendon loading tended to produce pilon fractures rather than calcaneal fractures [32]. Surprisingly, greater knee flexion was found to contribute to increased loading in both the rearfoot and the ankle joint, suggesting that less knee flexion during braking is safer. This could be a consequence of the muscle activations and upper body postures that were associated with this increased knee flexion. The knee angle during braking is not only influenced by muscle coordination (as in the present model), but also by seat position. Further model simulations, with variations in seat position, will be needed before we can generalize the conclusion that braking postures with less knee flexion are safer.

In addition to impact forces, kinematic variables can predict injuries. Ankle injuries from a crash have been associated with a dorsiflexion threshold of $45 \mathrm{deg}$ [36]. In our results dorsiflexion surpassed $45 \mathrm{deg}$ for roughly $10 \%$ of the simulations. The ankle joint force for these cases ranged from 2000-7000 N suggesting that soft tissue injuries or dislocations could occur in isolation as well as in conjunction with calcaneal or pilon fractures.

The regression models had fairly low prediction errors for peak post-impact forces $(360 \mathrm{~N}-585 \mathrm{~N}$, Table 3$)$, less than $10 \%$ of the force levels required for fracture, and can thus be used as an alternative to the original crash simulation model. The coefficients of the regression model have no physical meaning, and should only be used when combined into Eq. (1). Coefficient errors (Table 4) could have been reduced arbitrarily by using a larger number of crash simulations in the regression analysis and are therefore not directly useful. These may, however, be interpreted as indicating that there was sufficient data to obtain stable regression models in spite of correlations between the terms in Eq. (1). The RMSE values reported for the regression models (Table 3 ) are a more practically useful measure of model quality, but these pertain only to the following conditions: (1) brake pedal forces from $100 \mathrm{~N}$ to $1200 \mathrm{~N}$, (2) knee angles from $-40 \mathrm{deg}$ to $-110 \mathrm{deg}$, and (3) heel distances from $0 \mathrm{~m}$ to $0.25 \mathrm{~m}$.

The regression models that predict fracture-related forces from initial brake pedal force, knee angle and heel distance (Tables $3-4$ ), may be useful not only for injury prevention but also for accident analysis. If these values before impact are known, as well as the type of injury that occurred, an injury mechanism may possibly be reconstructed.

\section{Conclusions}

Based on the results of this study, we conclude the following.

1. Foot and ankle forces during a collision depend on initial lower extremity posture and brake pedal force.

2. Braking postures with increased knee flexion, while keeping the seat position fixed, are associated with higher foot and ankle forces during a collision.

\section{Acknowledgment}

This research was supported by the Aircast Foundation.

\section{References}

[1] MacKensie, E. J., Cushing, B. M., and Jurkovich, G. J., 1993, "Physical Impairment and Functional Outcomes Six Months After Severe Lower Extremity Fractures," J. Trauma, 34, 528-561.

[2] Parenteau, C. S., Viano, D. C., Lovsund, P., and Tingvall, C., 1996, "FootAnkle Injuries: Influence of Crash Location, Seating Position and Age," Accid. Anal Prev., 28, 607-617.

[3] Pattimore, D., Ward, E., Thomas, P., and Bradford, M., 1990, “The Nature and the Cause of Lower Limb Injuries in Car Crashes," in Proceedings of the 34th Stapp Car Crash Conference, Society of Automotive Engineers 912901, pp. $177-188$.

[4] States, J. D., 1986, “Adult Occupant Injuries of the Lower Limb," in Biomechanics and Medical Aspects of Lower Limb Injuries, Society of Automotive Engineers 861927, pp. 97-107.

[5] Martin. P. G., Crandall, J. R., Pilkey, W. D., and Miller, T. R., 1997, "Passenger Car Drivers: Annual Injury Incidence and Costs Projected to 2005," in Proceedings oF the Association for the Advancement of Automotive Medicine, Orlando, FL.

[6] Pletschen, B., Scheunert, D., Deubert, M., Hermann, R., and Zeidler, F., 1990, "Application of the injury cost scale (ICS) to Mercedes-Benz accident data," in Proceedings of the 34th Stapp Car Crash Conference, Society of Automotive Engineers, pp. 357-369.

[7] Burgess, A. R., Dischinger, P. C., O’Quinn, T. D., and Schmidhauser, C. B., 1995, "Lower Extremity Injuries in Drivers of Airbag-Equipped Automobiles: Clinical and Crash Reconstruction Correlations," J. Trauma: Inj., Infect., Crit. Care, 38, 509-516.

[8] Martin, P. G., Crandall, J. R., and Pilkey, W. D., 2000, "Injury Trends of Passenger Car Drivers in Frontal Crashes in the USA," Accid. Anal Prev., 32, 541-557.

[9] Siegel, J. H., Mason-Gonzalez, S., Dischinger, P., Cushing, B., Read, K., Robinson, R., Smialek, J., Heatfield, B., Hill, W., Bents, F. et al., 1993, "Safety Belt Restraints and Compartment Intrusion in Frontal and Lateral Motor Vehicle Crashes: Mechanisms of Injuries, Complications and Acute Care Costs," J. Trauma, 34, 736-758.

[10] Crandall, J. R., Kuppa, S. M., Klopp, G. S., Hall, G. W., and Hurwitz, S. R., 1998, "Injury Mechanisms and Criteria For the Human Foot and Ankle Under Axial Impacts to the Foot," I. J. Crash, 3, 147-161.

[11] Manning, P., Wallace, A., Owen, C., Roberts, A., Oakley, C., and Lowne, R., 1998, "Dynamic Response and Injury Mechanism in the Human Foot and Ankle and an Analysis of Dummy Biofidelity," in Proceedings of the 16th International Technical Conference on the Enhanced Safety of Vehicles, Windsor, Ontario, pp. 1960-1998.

[12] Rudd, R. W., Sieveka, E. M., Crandall, J. R., Pellettiere, J., Lynn, S., and Keller, J., 1998, "Lower Extremity and Brake Pedal Interaction in Frontal Collisions: Computer Simulation," Society of Automotive Engineers, 980364 , pp. $822-828$.

[13] Crandall, J. R., Portier, L., Petit, P., Hall, G. W., Bass, C. R., Klopp, G. S., Hurwitz, S., Pilkey, W. D., Trosseille, X., Tarriere, C., and Lassau, J., 1996, "Biomechanical Properties of the Leg, Foot and Ankle," in Proceedings of the 40th Stapp Car Crash Conference, Society of Automotive Engineers 962424, pp. 173-192.

[14] Gerritsen, K. G., van den Bogert, A. J., and Nigg, B. M., 1995, "Direct Dynamics Simulation of the Impact Phase in Heel Toe Running," J. Biomech., 28, 661-668.

[15] Kitagawa, Y., Ichikawa, H., Pal, C., King, A. I., and Levine, R. S., 1998, "Lower Leg Injuries Caused by Dynamic Axial Loading and Muscle Tensing," in Proceedings of the 16th International Technical Conference on the Enhanced Safety of Vehicles, Windsor, Ontario, pp. 1597-1607.

[16] Neptune, R. R., Wright, I. C., and van den Bogert, A. J., 2000, “The Influence of Orthotic Devices and Vastus Medialis Strength and Timing on Patellofemoral Loads During Running," Clin. Biomech., 15, 611-618.

[17] Cole, G. K., Nigg, B. M., van den Bogert, A. J., and Gerritsen, K. G., 1996a, "Lower Extremity Joint Loading During Impact in Running," Clin. Biomech., 11, 181-193.

[18] Bernstein, N., 1967, The Coordination and Regulation of Movements, Pergamon Press, London.

[19] Cole, G. K., van den Bogert, A. J., Herzog, W., and Gerritsen, K. G., 1996b, "Modeling of Force Production in Skeletal Muscle Undergoing Stretch," Clin. Biomech., 29, 1091-1104.

[20] Winter, D. A., 1990, Biomechanics and Motor Control of Human Movement, 2nd ed., Wiley, New York, NY.

[21] Robbins, D. H., 1983, “Anthropometric Specifications For a Mid-Sized Male Dummy," U.S. Department of Transportation DTNH22-80-C-07502, Washington, D.C., Vol. 2.

[22] Dempster, W. T., 1956, "The Anthropometry of Body Action," Ann. N.Y. Acad. Sci., 63, 559-585.

[23] Gerritsen, K. G. M., van den Bogert, A. J., Hulliger, M., and Zernicke, R. F. 1998, "Intrinsic Muscle Properties Facilitate Motor Control-A Computer Simulation Study," Motor Control, 2, 206-220.

[24] McLean, S. G., Su, A., and van den Bogert, A. J., 2003, "Development and Validation of a 3-D Model to Predict Knee Joint Loading During Dynamic Movement," ASME J. Biomech. Eng., 125, 864-874.

[25] Reiner, R., and Edrich, T., 1999, "Identification of Passive Elastic Joint Moments in the Lower Extremities," J. Biomech., 32, 539-544.

[26] Wright, I. C., Neptune, R. R., van den Bogert, A. J., and Nigg, B. M., 1998, "Passive Regulation of Impact Forces in Heel-Toe Running," Clin. Biomech., 13, 521-531.

[27] Aerts, P., and De Clercq, D., 1993, "Deformation Characteristics of the Heel Region of the Shod Foot During a Simulated Heel Strike: The Effect of Varying Midsole Hardness," J. Sports Sci., 11, 449-461.

[28] Code of Federal Regulations: Seat Belt Assemblies, 2000, Federal Motor Vehicle Safety Standards, 49CFR571.209, DOT, Washington, D.C, http:// www.access.gpo.gov/nara/cfr/waisidx 00/49cfr571 00.html. 
[29] Digges, K. H., Bedewi, P. G., Nahouth, G. T., Bedewi, N. E., Augenstein, J., Perdeck, E., and Stratton, J., 1995, "Determination and Modeling of Ankle Injury Causation," in Proceedings of the International Conference on Pelvic and Lower Extremity Injuries, Washington, D.C.

[30] Yoganandan, N., Pintar, F. A., and Seipel, R., 2000, "Experimental Production of Extra- and Intra-Aticular Fractures of the OS Calcis," J. Biomech., 33, $745-749$.

[31] Dubbeldam, R., Nilson, G., Pal, B., Eriksson, N., Owen, C., Roberts, A., Crandall, J., Hall, G., Manning, P., and Wallace, A., 1999, “A MADYMO Model of the Foot and Leg For Local Impacts," in Proceedings of the 43rd Stapp Car Crash Conference, Society of Automotive Engineers 99SC12.

[32] Funk, J. R., Crandall, J. R., Tourret, L. J., MacMahon, C. B., Bass, C. R., Patrie, J. T., Khaewpong, N., and Eppinger, R. H., 2002, “The Axial Injury
Tolerance of the Human Foot/Ankle Complex and the Effect of Achilles Tension," ASME J. Biomech. Eng., 124, 750-757.

[33] Cappon, H. J., van den Kroonenberg, A. J., Happee, R., and Wismans, J., 1999 "An Improved Lower Leg Multibody Model," Proceedings of the International Conference on the Biomechanics of Impacts IRCOBI, Sitges, Barcelona, Spain, eds. A. Charpenne and M. Mackay, pp. 499-512.

[34] Fildes, B., Lenard, J., Lane, J., Vulcan, P., and Seyer, K., 1997, “Lower Limb Injuries to Passenger Car Occupants," Accid. Anal Prev., 29, 785-791.

[35] Donnelly, B. R., Galganski, R. A., Lawrence, R. D., and Blatt, A., 2001, "Crash Reconstruction and Injury-Mechanism Analysis Using Event Data Recorder Technology," Annual Proceedings of the Association for Advancement of Automotive Medicine 45, 331-351.

[36] Begeman, P. C., and Prasad, P., 1990, "Human Ankle Response in Dorsiflexion," in Proceedings of the 34th Stapp Car Crash Conference, Society of Automotive Engineers, pp. 39-53. 